\title{
Modelo experimental de reconstrução em falha mandibular em coelhos
}

\author{
Experimental model of reconstruction in mandibular defect in rabbit
}

\author{
Cristiano Gomes ${ }^{\mathrm{I}}$ Mariane Brascher Elizeire ${ }^{\mathrm{II}}$ Paula Becker ${ }^{\mathrm{II}}$ Lisiane Foerstnow ${ }^{\mathrm{II}}$ Gisele Stein ${ }^{\mathrm{II}}$ \\ Marcelo Meller AlieviI Elizabeth Obino Cirne-LimaII Emerson Antonio Contesini ${ }^{\text {II }}$
}

\section{RESUMO}

Este trabalho tem como objetivo apresentar um novo modelo experimental de reconstrução em falha mandibular em coelhos. Foram utilizados 14 animais, nos quais, em uma primeira etapa, extraiu-se cirurgicamente o dente incisivo inferior esquerdo permanente. Após um período de 50 dias para o preenchimento ósseo do alvéolo dentário, foi realizada a cirurgia. Inicialmente, coletou-se $10 \times 5 \times 5 \mathrm{~mm}$ de enxerto ósseo autógeno da crista ilíaca e, em seguida, foi procedida uma falha mandibular parcial de mesmo tamanho, que foi preenchida com o enxerto e fixada com microplaca de titânio. Os coelhos foram submetidos a avaliações clínicas e radiográficas, sendo sete submetidos a eutanásia aos 15 dias e os demais aos 30 dias para análise macro $e$ microscópica. A ingestão de água e ração não foi comprometida, e os animais não apresentaram algia, dificuldade de mastigação e de apreensão. Somente um animal apresentou rejeição a um parafuso, sem ocorrer o deslocamento da placa nem do enxerto. Esse método mostrouse eficaz como modelo experimental de reconstrução em falha mandibular de coelhos, demonstrando a evolução cicatricial óssea do enxerto por meio dos exames radiográficos, macroscópicos e microscópicos aos 15 e 30 dias.

Palavras-chave: mandíbula, cirurgia, enxerto, bucomaxilofacial, microplaca.

\section{ABSTRACT}

This paper aims to present a new experimental model of mandibular defect reconstruction in rabbits. It was used 14 animals, in which, in a first stage the left permanent inferior incisive tooth was extracted surgically. After a 50 days period for the bone to fulfill the dentary alveolus, surgery was performed. At first, a $10 \times 5 \times 5 \mathrm{~mm}$ autograft was removed form the iliac crest, following a partial mandibular failure in the bone with the same auto graft size which was filled with the graft and fixed using titanium microplate. The rabbits were submitted to clinical and radiographic evaluation and 7 of them were euthanasiated at 15 days and the other 7 at 30 days to macro and microscopic analysis. The water and commercial food ingestion was not compromised, and the animals did not showed any chewing or apprehension difficulties, neither pain. Only one animal presented rejection to one screw, without occurring micro plate nor auto graft dislocation. This method showed to be efficient for an experimental model of reconstruction in mandibular defects of rabbits, demonstrating a healing evolution of the graft through radiographic, macroscopic and microscopic exams in $15^{\text {th }}$ and $30^{\text {th }}$ days.

Key words: jaw, surgery, graft, bucomaxillofacial, microplate.

\section{INTRODUÇÃO}

As falhas ósseas da mandíbula, tanto em humanos, quanto em animais, podem ser causadas por remoção de neoplasias, trauma e infecções ou constituir deformidade congênita (BRANDÃO \& ARAÚJO, 1989, VERSTRAETE \& OSOFSKY, 2005). As técnicas de reconstrução mandibular têm representado um desafio para os cirurgiões bucomaxilofaciais e ortopedistas (LI \& LI, 2005). Para

\footnotetext{
IPrograma de Pós-graduação em Medicina Veterinária, Departamento de Clínica de Pequenos Animais, Laboratório de Cirurgia Experimental, Universidade Federal de Santa Maria (UFSM). Endereço para correspondência: Av. Bento Gonçalves 9090, 91540000, Porto Alegre, RS, Brasil. E-mail: crisgomes98@hotmail.com.

IFFaculdade de Veterinária, Universidade Federal do Rio Grande do Sul, Porto alegre, RS, Brasil.
} 
o preenchimento do defeito, geralmente opta-se pelo autoenxerto, aloenxerto ou xenoenxerto, sendo o primeiro o que apresenta os melhores resultados, por não produzir rejeição e conter células vivas (GANDELMANN et al., 2003). É de extrema importância que o período de recuperação das funções orais seja breve, para uma melhor apreensão, mastigação e deglutição dos alimentos. Além disso, a falha produzida é de difícil cicatrização, principalmente nos idosos, em que a frequência de tumores é maior e a consolidação mais lenta (ELLIS, 2005). Para isso, muitos estudos vêm sendo desenvolvidos na área da engenharia tecidual a fim de buscar alternativas que reduzam o tempo de cicatrização dos tecidos e minimizem as possíveis complicações de cada método (BIANCO \& ROBEY, 2001; CANCEDDA et al., 2003; MAO et al., 2006).

Os coelhos têm sido amplamente usados como modelo experimental em diferentes processos que avaliam a cicatrização óssea. Alguns estudos demonstraram a utilização desses animais para avaliação de diferentes métodos de osteogênese por distração (AIDA et al., 2003; CLARK et al., 2006). KAHNBERG et al. (1998) publicaram um modelo experimental com coelhos para o estudo de enxertos ósseos onlay. Outro modelo experimental foi descrito por LUNDGREN et al. (1997). O procedimento consistia em promover um defeito na maxila dos coelhos, entre o incisivo e o primeiro molar, sem a colocação de qualquer material nesse local.

Este trabalho tem como objetivo apresentar um novo modelo experimental de reconstrução de falha óssea utilizando autoenxerto e microplaca com parafusos de titânio em coelhos.

\section{MATERIAIS E MÉTODOS}

Para a elaboração do experimento, foram utilizados 14 coelhos (Oryctolagus cuniculus) da raça Nova Zelândia albinos, hígidos, com massa corporal média de $3 \mathrm{~kg}$ e aproximadamente 90 dias de idade. Os animais foram avaliados clinicamente e alojados em gaiolas individuais, onde receberam como alimento ração comercial específica para coelhos e água ad libitum. Os 14 coelhos foram separados aleatoriamente em dois grupos de sete animais e eutanasiados aos 15 ou aos 30 dias. Primeiramente, foram submetidos à extração do dente incisivo inferior esquerdo, tendo sido respeitado um período mínimo de 50 dias para recuperação do alvéolo dentário, a fim de liberar a região para realização da falha óssea. As extrações dentárias foram feitas após pré-anestesia com cetamina, midazolan e fentanila por via intramuscular (IM), sendo os animais mantidos sob anestesia inalatória com isofluorano ao efeito com máscara. Efetuou-se a sutura da mucosa com fio absorvível sintético multifilamentar 4-0 com pontos isolados simples.

Após o período de 50 dias, os animais foram anestesiados com medicação pré-anestésica com midazolan, cloridrato de meperidina e cetamina. Com a palpação da cartilagem laríngea, os animais foram intubados e foi iniciada a anestesia inalatória, e estes foram mantidos com isofluorano ao efeito. Durante o transoperatório, para ampliar o poder analgésico, utilizou-se o cloridrato de fentanila IV, a cada 30 minutos. Posteriormente à aplicação da medicação pré-anestésica, foi realizada a tricotomia ampla das áreas a serem operadas e foi obtido o acesso venoso na veia marginal da orelha, por onde se procedeu à administração de solução salina ( $\mathrm{NaCl}$ 0,9\%) e ampicilina sódica, 20 minutos antes do procedimento cirúrgico. Por fim, com o coelho em decúbito lateral, a antissepsia da pele foi promovida com o uso de solução de clorexidine a $0,12 \%$, seguida pela colocação dos panos de campo plástico estéreis.

Foi realizada a coleta do autoenxerto corticoesponjoso da crista ilíaca de aproximadamente 10x5x5mm (Figura 1A), com o auxílio de uma broca diamantada cônica acoplada a um motor de baixa rotação, acondicionada em cuba de solução salina ( $\mathrm{NaCl}$ 0,9\%) estéril e morna. O fechamento do subcutâneo e da pele foi realizado com fio mononáilon 4-0, em padrão interrompido simples. O acesso cirúrgico da mandíbula deu-se por uma incisão extraoral e promoveu-se a remoção de, aproximadamente, $10 \times 5 \times 5 \mathrm{~mm}$ de segmento entre a sínfise mandibular e o primeiro molar (Figura 1B). Após essa etapa, a falha óssea foi preenchida com o enxerto, que foi fixado com microplaca de titânio de quatro furos sem espaçamento e dois parafusos de $5 \mathrm{~mm}$, também de titânio, sendo um na porção cranial da mandíbula e outro no orifício seguinte, caudalmente ao primeiro parafuso, fixando assim o autoenxerto da crista ilíaca. Outro parafuso de $7 \mathrm{~mm}$, também de titânio, foi colocado no último orifício caudal da microplaca (Figura 1C). Por fim, o fechamento da ferida foi promovido, com fio mononáilon 4-0, no padrão contínuo simples para a aproximação dos tecidos e com ponto isolado simples para o fechamento da pele. Os animais receberam, ao final da cirurgia e nos dois dias subsequentes, cetoprofeno e cloridrato de tramadol, além de antibioticoprofilaxia sistêmica com 


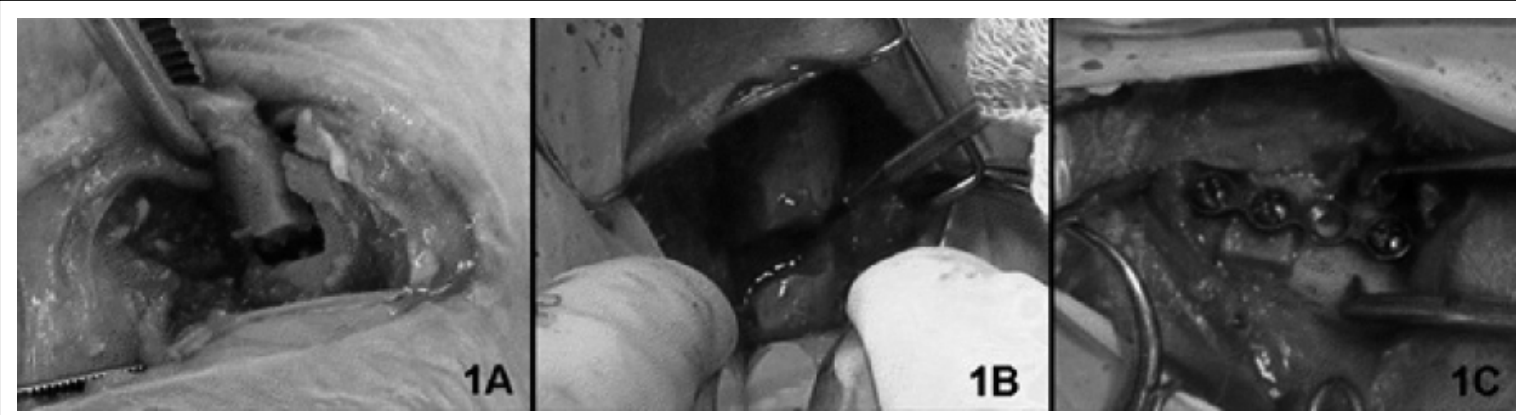

Figura 1 - A. Coleta do autoenxerto corticoesponjoso da crista ilíaca de 10x5x5mm. B. Realização da falha mandibular de 10x5x5mm entre a sínfise da mandíbula e o primeiro molar com o auxílio de uma broca cônica de baixa rotação. C. Fixação do autoenxerto de crista ilíaca com a utilização de microplaca de titânio de quatro furos, sem espaçamento.

enrofloxacina durante os primeiros sete dias de pósoperatório.

Para a avaliação clínica, os animais foram diariamente inspecionados, durante sete dias após o procedimento cirúrgico. Observaram-se o comportamento dos coelhos quanto ao retorno da alimentação com ração comercial, a restauração da mastigação e deglutição, a dor e o edema local. A avaliação radiográfica foi realizada aos zero, sete, 14 , 21 e 28 dias após a cirurgia. Foram realizadas duas projeções, sendo uma lateral obliquada a $45^{\circ}$ e outra fronto-mandibular. Por meio das radiografias, foi avaliado o alinhamento do enxerto ósseo em relação aos segmentos proximal e distal da mandíbula, a estabilidade da microplaca, a migração dos parafusos, os sinais de consolidação das interfaces osso/enxerto e a formação de ponte óssea. A união radiográfica foi considerada presente quando existia continuidade cortical completa na interface osso/enxerto e os calos, periosteal e endosteal se apresentavam com remodelamento ativo.

Ao término dos períodos de avaliações (15 e 30 dias), todos os animais foram eutanasiados, com a utilização de tiopental sódico e solução de cloreto de potássio até a parada cardiorrespiratória, seguindo as normas estipuladas para eutanásias em animais pelo Conselho Federal de Medicina Veterinária (CFMV). A porção operada da mandíbula foi avaliada quanto à existência de reação dos tecidos moles e qualidade do calo ósseo, aos sinais de infecção, ao aspecto e à estabilidade da microplaca, dos parafusos e do enxerto ósseo. Após a remoção da microplaca e dos parafusos, a mandíbula foi colocada em solução de formalina tamponada a $10 \%$ para a subsequente avaliação histológica. Foram realizados cortes histológicos com espessura de quatro micras; as lâminas foram coradas pela técnica de hematoxilina e eosina (HE) e examinadas em microscópio óptico.

\section{RESULTADOS E DISCUSSÃO}

O modelo animal escolhido para a realização deste trabalho demonstrou uma fácil manipulação desses animais durante todas as etapas, um baixo custo de manutenção, bem como permitiu uma boa estrutura anatômica para a elaboração dos procedimentos cirúrgicos e radiográficos. Modelos animais maiores, como cães, ovelhas e cabras, têm demonstrado ser um bom método para avaliação do reparo ósseo de mandíbula, fêmur e tíbia, sendo utilizada a engenharia tecidual, mimetizando situações clínicas reais (CANCEDDA et al., 2007); entretanto, essas espécies apresentam alto custo e dificuldade de manutenção. Outro importante fator nessa decisão foi a análise de várias pesquisas que fizeram uso desses animais para verificação do processo de cicatrização óssea em mandíbula (RANTA et al., 1981; SHIROTA et al., 1991; KAHNBERG, 1998). LUNDGREN et al. (1997) ainda destacaram que modelos de defeitos maxilares estão sujeitos ao estresse da mastigação, refletindo a realidade clínica durante a cicatrização dessas falhas.

O porte físico dos animais e a dimensão da área da mandíbula permitiram a realização de uma falha mandibular de $10 \times 5 \times 5 \mathrm{~mm}$, considerada por LI \& LI (2005) um defeito ósseo crítico em coelhos. A região estudada foi bem identificada por meio dos exames radiográficos, assim como descrito por LUNDGREN et al. (1997). Em experimentos em que se utilizaram ratos para a avaliação da regeneração óssea em falhas mandibulares, o método adotado foi somente a histopatologia, e não a análise radiográfica (AROSARENA et al., 2003; AROSARENA\& COLLINS, 2005; SOCCOL et al., 2006). Isso pode ter ocorrido justamente pela dificuldade de visibilizar essas estruturas, em razão de seu tamanho anatômico.

A técnica de VERSTRAETE \& OSOFSKY (2005) utilizada para a extração dentária mostrou-se 
rápida e de fácil execução, não apresentando quaisquer complicações em nenhum dos coelhos, embora deva ser efetuada de forma cuidadosa para evitar danos às estruturas mandibulares e dentárias. Os autores contraindicam os movimentos rotacionais do fórceps durante a extração. Complicações como avulsão do osso alveolar, fratura do dente ou ainda o recrescimento deste por permanência do tecido germinal dental podem ocorrer. Entretanto, foi necessária a realização cuidadosa desses movimentos para facilitar a remoção, não acarretando nenhuma complicação.

Todos os coelhos apresentaram excelente recuperação, não havendo necessidade de mudança na sua alimentação. A recuperação do alvéolo dentário ocorreu em todos os animais após 50 dias da extração, como recomendado por SHIROTA et al. (1991). A realização desse procedimento foi fundamental para permitir a criação de um defeito ósseo crítico na mandíbula, sem danificar as estruturas dentárias. Também foi possível associar um método de fixação interna rígida com microplacas e parafusos, para permitir uma boa estabilização do enxerto.

A crista ilíaca ofereceu um bom local para obtenção de enxerto ósseo; além de ter fácil acesso, forneceu quantidade suficiente de enxerto para o preenchimento da falha proposta neste estudo, permitindo mimetizar uma situação clínica real. Os outros locais de obtenção de enxertos autógenos, provavelmente, não proporcionariam a oclusão dessa falha, como também dificultariam a coleta e manipulação.

As microplacas demonstraram a mesma facilidade de manuseio relatado pela literatura, favorecendo, portanto, a manipulação das delicadas estruturas da mandíbula de coelhos e levando também ao mínimo trauma dos tecidos adjacentes (BILGILI \& KURUM, 2003). Elas propiciaram fixação rígida, mantendo máxima imobilização do enxerto ósseo no defeito mandibular. Um coelho apresentou rejeição do parafuso cranial, eliminando-o entre o $7^{\circ}$ e o $14^{\circ}$ dia pós-operatório, sem ocorrer o deslocamento do enxerto nem a desestabilização da placa, fato que pode ter ocorrido pelo desgaste excessivo da broca ao promover o orifício, o que causou instabilidade do parafuso e, consequentemente, aumentou as possibilidades de afrouxamento. Porém, essas placas mostraram-se eficazes na fixação do enxerto, podendo ser uma alternativa não somente nos modelos experimentais, como também na rotina dos pacientes veterinários.

A proposta inicial era promover uma falha segmentar total da mandíbula. Porém, as avaliações anatômica e radiográfica e de cirurgias em pilotos identificaram grande dificuldade em realizá-la e possibilidade de complicações pós-cirúrgicas, fato não observado neste experimento. Além disso, outros trabalhos que tinham o objetivo de analisar a cicatrização em falhas mandibulares não a promoviam por completo, o que consolidou a ideia de não realizar falha completa para essa análise (SHIROTA et al., 1991; LUNDGREN et al., 1997; KAHNBERG et al., 1998). Durante as avaliações clínicas, não foram observadas quaisquer alterações relacionadas à mastigação e à deglutição, com os animais se alimentando normalmente com ração comercial já no primeiro dia pós-operatório. Os animais não apresentaram sinal relacionado à dor nem edema no local cirúrgico.

Formação de aderência na região operada foi observada com 15 dias de evolução, sendo possível distinguir o enxerto do tecido ósseo circunjacente. Na avaliação macroscópica de 30 dias, o tecido permaneceu com aderências; entretanto, não foi notada a diferença entre o tecido e a estrutura neoformada, constatando-se evolução da reparação óssea dos animais do grupo 15 dias com relação ao grupo 30 dias. Não se observou mobilidade entre o fixador interno e o enxerto, exceto no caso do animal em que ocorreu a perda de um dos parafusos. Nenhum sinal de contaminação, como, por exemplo, formação de exsudato ou mudança de coloração tecidual da região, foi percebido. Nas análises histopatológicas com 15 dias de período pósoperatório, os enxertos ósseos eram facilmente visualizados, e a atividade das células fagocitárias foi intensa (Figura 2A). Já aos 30 dias, a visualização foi mais difícil, e o implante era visto na forma de resquício. A coaptação dos bordos foi mais frequente na forma de ligação por tecido fibroso. Associações cartilaginosas e ósseas também ocorreram de forma significativa (Figura 2B). Esses dados confirmam a regeneração da falha óssea aos 15 e 30 dias. Nos animais do grupo 30 dias, esse processo encontravase em um estágio mais avançado, com intensa reabsorção do enxerto, corroborandocom os achados macroscópicos aos 30 dias.

Nos estudos radiográficos, foi observado aumento gradativo da densidade óssea em 14,28\% dos animais aos sete dias e $92,85 \%$ aos 14 dias. Na avaliação radiográfica dos coelhos do grupo eutanasiado no $30^{\circ}$ dia, $100 \%$ apresentaram aumento da densidade óssea aos 21 dias, porém sem a evidência de formação de ponte óssea, fato observado em 42,85\% desses animais aos 28 dias, comprovando a evolução do processo cicatricial em todos os animais deste estudo. 


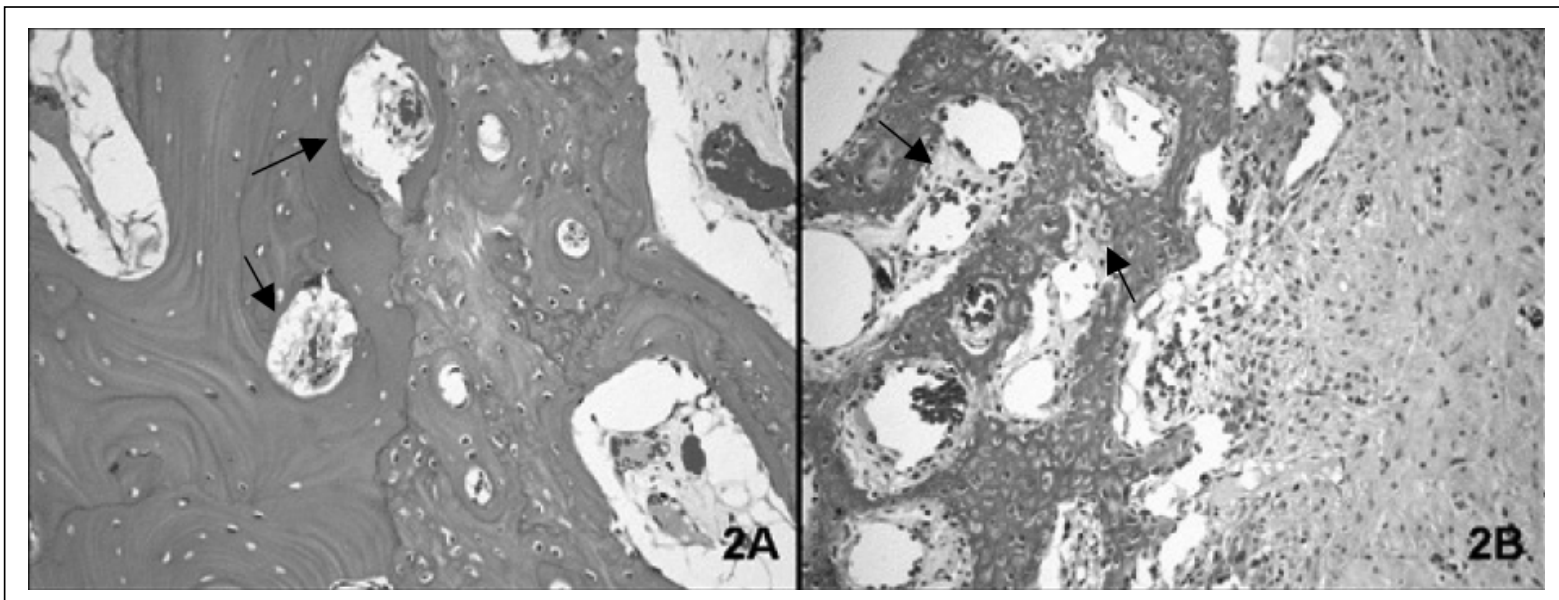

Figura 2 - A. Imagem histopatológica (HE objetiva 20x.) de um coelho GCT15 apresentando remodelação óssea pelas células fagocitárias e formação vascular (setas). B. Imagem histopatológica (HE objetiva 20x) de um coelho CGT30 mostrando remodelação (setas) e coaptação óssea por meio de tecido fibroso com atividade intensa de osteoblastos e formação vascular.

\section{CONCLUSÃO}

Os resultados obtidos neste trabalho mostraram que o uso de microplacas de titânio permitiu a reconstrução da falha crítica mandibular de coelhos, fornecendo uma adequada estabilização do autoenxerto. Os animais retornaram às funções fisiológicas normais de mastigação e deglutição após a cirurgia, sem que houvesse quaisquer complicações relacionadas ao procedimento. Os resultados radiográficos, macroscópicos e microscópicos demonstraram a evolução do processo cicatricial em todos os animais deste experimento. Assim, o procedimento pode ser utilizado como modelo experimental em pesquisas que visem à busca de materiais que acelerem o processo cicatricial dos enxertos em falhas mandibulares.

\section{AGRADECIMENTOS}

Ao Conselho Nacional de Desenvolvimento Científico e Tecnológico (CNPq) e ao Hospital de Clínicas de Porto Alegre, pelo apoio financeiro concedido para a realização deste trabalho.

À PROMM comércio de implantes cirúrgicos por ceder as placas e parafusos para este experimento.

\section{COMITÊ DE ÉTICA E BIOSSEGURANÇA}

O trabalho foi aprovado pelo Comitê de Ética do Hospital de Clínicas de Porto Alegre (HCPA), protocolo 06402.

\section{REFERÊNCIAS}

AIDA, T. et al. Effect of latency in a rabbit mandibular distraction osteogenesis. International Journal of Oral e Maxillofacial Surgery, v.32, p.54-62, 2003.
AROSARENA, O.A.; COLLINS, W.L. Bone regeneration in the rat mandible with bone morphogenetic protein-2: a comparison of two carriers. Otolaryngology - Head and Neck Surgery, v.132, p.592-597, 2005.

AROSARENA, O.A. et al. Defect repair in the rat mandible with bone morphogenic proteins and marrow cells. Archives of Facial and Plastic Surgery, v.5, p.103-108, 2003.

BILGILI, H.; KURUM, B. Treatment of fractures of the mandible and maxilla by mini titanium plate fixation systems in dogs and cats. Australian Veterinary Journal, v.81, p.671-673, 2003

BRANDÃO, L.G.; ARAÚJO, V.J.F. Reconstrução mandibular. In: BRANDÃO, L.G.; FERRAZ, A.R. (Eds). Cirurgia de cabeça e pescoço. São Paulo: Roca, 1989. p.147-155.

CANCEDDA, R. et al. A tissue engineering approach to bone repair in large animal models and in clinical practice. Biomaterials, v.28, p.4240-4250, 2007.

CLARK, C.L. et al. Distraction osteogenesis in irradiated rabbit mandibles with adjunctive hyperbaric oxygen therapy. Journal of Oral Maxilofacial Surgery, v.64, p.589-593, 2006.

ELLIS, E. Reconstrução cirúrgica dos defeitos maxilares. In: PETERSON, L.J. (Ed). Cirurgia oral e maxilofacial contemporâneo. São Paulo: Elsevier, 2005. p.681-694.

GANDELMAN, I.H.A. et al. Enxertos e reconstruções ósseas em cirurgia dos tumores odontogênicos e não-odontogênicos. In: CARDOSO, R.J.A.; MACHADO, M.E.L. (Eds). Odontologia, arte e conhecimento: cirurgia, endodontia, periodontia e estomatologia. São Paulo: Artes Medicas, 2003. p.95-104.

KAHNBERG, K. et al. An experimental rabbit model for studying the healing of onlay bone grafts. Swed Dentistry Journal, v.22, p.15-21, 1998. 
LI, Z.; LI, Z. Repair of mandible defect with tissue engineering bone in rabbits. Surgical Research, v.75, p.1017-1021, 2005.

LUNDGREN, A.K. et al. An experimental rabbit model for jaw-bone healing. International Journal of Oral and Maxillofacial Surgery, v.26, p.461-464, 1997.

RANTA, R. et al. Transplantation of free tibial periosteal graft on alveolar bone defect in adult rabbit. International Journal of Oral Surgery, v.10, p.122-127, 1981.

SHIROTA, T. et al. An experimental study of healing around hydroxylapatite implants installed with autogenous iliac bone graft for jaw reconstruction. Journal of Oral Maxillofacial Surgery, v.49, p.1310-1315, 1991.

SOCCOL, A.T. et al. Comparação entre os bioenxertos de hidroxiapatita de cálcio e submucosa de intestino delgado porcino no preenchimento de defeitos ósseos criados em mandíbula de ratos. Revista Brasileira de Otorrinolaringologia, v.72, n.2, p.195-199, 2006 .

VERSTRAETE, F.J.M.; OSOFSKY, A. Dentistry in pet rabbits. Compendium on Continuing Education of the Practicing Veterinarian, v.9, p.671-682, 2005 . 